\title{
Erratum
}

\section{Intercellular junctions in the reticular lamina of the organ of Corti}

R. L. GULLEY and T. S. REESE

Journal of Neurocytology 5, 479-507

The publishers regret that Figure 36 was omitted from the above paper. We offer our apologies to the authors for this mistake, and to the readers of the Journal for any inconvenience caused.

Figure 36 is printed overleaf, and its caption is given below.

Fig. 36. Summary diagram illustrating the organization of junctions in the reticular lamina. This diagram is meant to schematize the organization of the various types of intercellular junctions and their related cytoplasmic coats, not to represent a single plane of section or to summarize all the cytological features of the various cell types. 


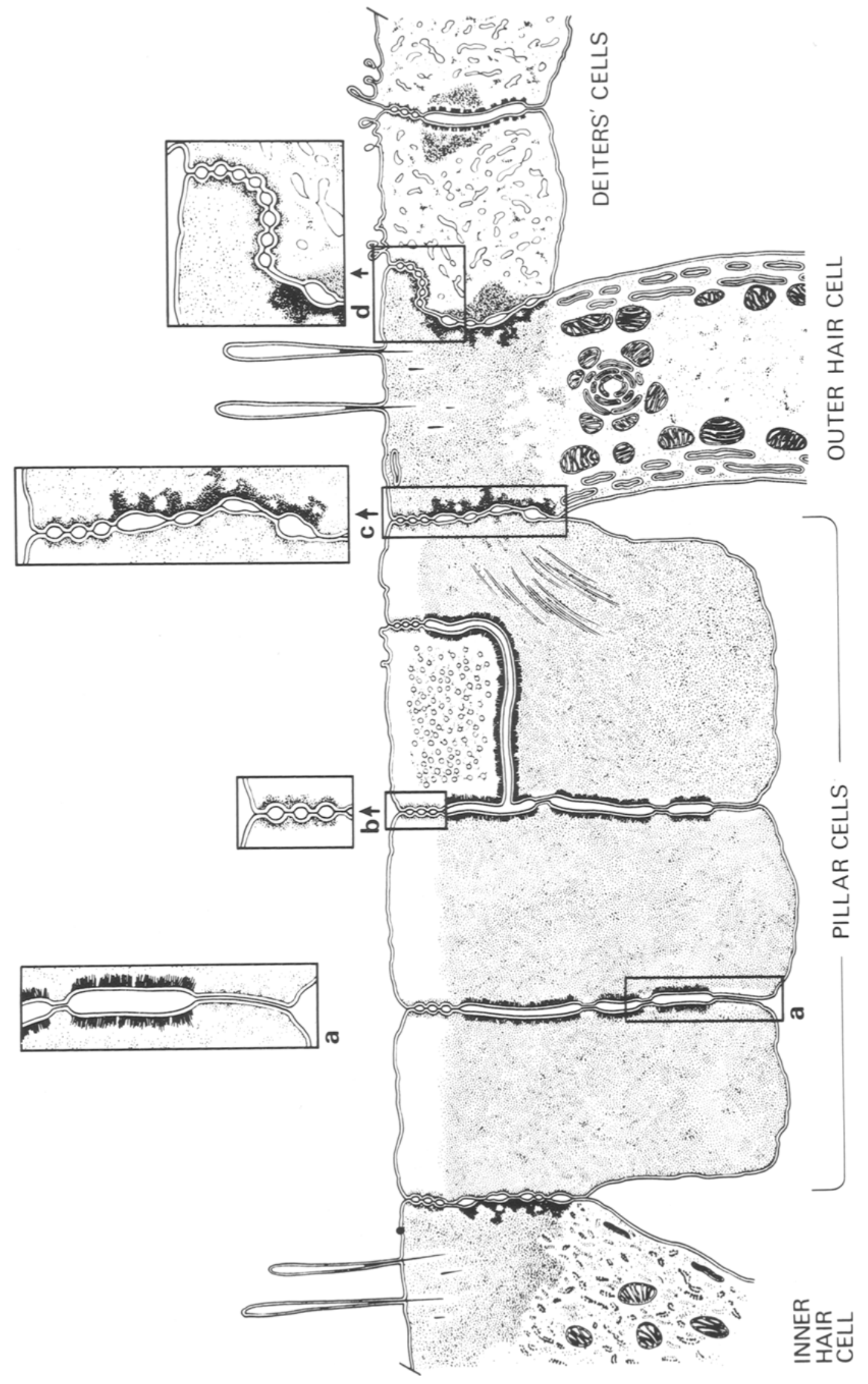

